\title{
TGF- $\beta 1$ alters esophageal epithelial barrier function by attenuation of claudin-7 in eosinophilic esophagitis
}

\author{
N Nguyen ${ }^{1,2,3}$, SD Fernando ${ }^{1,2,3}$, KA Biette ${ }^{2,3}$, JA Hammer ${ }^{2,3}$, KE Capocelli ${ }^{1,2,4}$, DA Kitzenberg ${ }^{3,5}$, \\ LE Glover $^{3,5}$, SP Colgan ${ }^{3,5}$, GT Furuta ${ }^{1,2,3}$ and JC Masterson ${ }^{1,2,3,6}$
}

Barrier dysfunction has been implicated in the pathophysiology of eosinophilic esophagitis (EoE). Transforming growth

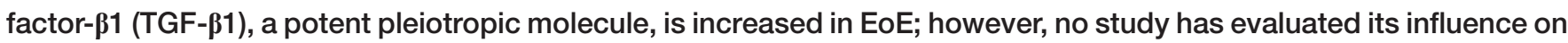
esophageal epithelial barrier. We hypothesized that TGF- $\beta 1$ regulates barrier dysfunction in EoE. We aimed to determine the role of TGF- $\beta 1$ in the epithelial barrier in models of EoE. To examine the impact of TGF- $\beta 1$ on esophageal barrier, immortalized human esophageal epithelial (EPC2-hTERT) cells were exposed to TGF- $\beta 1$ during the three-dimensional air-liquid interface (3D-ALI) model in vitro. TGF- $\beta 1$ exposure diminished EPC2-hTERT barrier function as measured by transepithelial electrical resistance (TEER) and $3 \mathrm{kDa}$ Fluorescein isothiocyanate dextran paracellular flux (FITC Flux), and hematoxylin and eosin (H\&E) assessment revealed prominent cellular separation. In analysis of epithelial barrier molecules, TGF- $\beta 1$ led to the specific reduction in expression of the tight-junction molecule, claudin-7 (CLDN7), and this was prevented by TGF- $\beta$-receptor I inhibitor. Short hairpin ribonucleic acid (shRNA)-mediated CLDN7 knockdown diminished epithelial barrier function, whereas CLDN7 overexpression resulted in protection from TGF- $\beta 1$-mediated barrier dysfunction. In pediatric EoE biopsies CLDN7 expression was decreased and altered localization was observed with immunofluorescence analysis, and the TGF- $\beta 1$ downstream transcription factor, phosphorylated SMAD2/3 (pSMAD2/3), was increased. Our data suggest that TGF- $\beta 1$ participates in esophageal epithelial barrier dysfunction through CLDN7 dysregulation.

\section{INTRODUCTION}

Eosinophilic esophagitis (EoE) is a chronic, immune/antigenmediated, inflammatory disease characterized by esophageal dysfunction and dense esophageal eosinophilia. ${ }^{1}$ The esophageal epithelial architecture of patients with EoE is disrupted, characterized by dilated intercellular spaces and prominent basal cell hyperplasia. ${ }^{2}$ A growing body of evidence implicates altered esophageal epithelial barrier in the pathophysiology of EoE. For instance, studies have shown decreased cell adhesion molecules such as desmoglein and epithelial barrier molecules such as filaggrin in EoE. ${ }^{3-5}$ In addition, others have demonstrated barrier dysfunction in EoE patients at the electrophysiological level, suggesting impaired esophageal mucosa integrity. ${ }^{6}$ Our previous work also demonstrated altered ultrastructural features with decreased desmosomes in active EoE. ${ }^{7}$ To date, molecular mechanisms focused on the impact of type- 2 cytokines, particularly interleukin-13, on regulating molecules associated with the esophageal epithelial barrier. ${ }^{3,4}$

An increasing body of evidence suggests that transforming growth factor- $\beta 1$ (TGF- $\beta 1$ ), a pleiotropic cytokine that has a critical role in immunoregulation, fibrosis, and remodeling, participates in the pathogenesis of EoE. TGF- $\beta 1$ signaling is increased in subjects with EoE and TGF- $\beta 1$ itself is produced by

${ }^{1}$ Section of Pediatric Gastroenterology, Hepatology and Nutrition, Digestive Health Institute, Children's Hospital Colorado, Aurora, Colorado, USA. ${ }^{2}$ Gastrointestinal Eosinophilic Diseases Program, Department of Pediatrics, University of Colorado School of Medicine, Aurora, Colorado, USA. ${ }^{3} \mathrm{Mucosal}$ Inflammation Program, University of Colorado School of Medicine, Aurora, Colorado, USA. ${ }^{4}$ Department of Pathology, Children's Hospital Colorado, Aurora, Colorado, USA. ${ }^{5}$ Department of Medicine, University of Colorado School of Medicine, Aurora, Colorado, USA and ${ }^{6}$ Institute of Immunology, Department of Biology, Maynooth University, Maynooth, Co. Kildare, Ireland. Correspondence: JC Masterson (joanne.masterson@ucdenver.edu) 
a number of different cells including eosinophils, epithelial cells, and mast cells. ${ }^{8-11}$ Although TGF- $\beta 1$ protein has been difficult to quantify in esophageal tissue affected by EoE, biopsy specimens from subjects with EoE have demonstrated increased TGF- $\beta 1$ mRNA and phosphorylated SMAD2/3 (pSMAD2/3) transcription factor protein immunostaining, a downstream nuclear signaling molecule in the TGF- $\beta 1$ signaling pathway. ${ }^{8,12,13}$ Studies have also shown that TGF$\beta 1$ has a critical role in esophageal remodeling, participates in esophageal smooth muscle contraction, stimulates fibroblast secretion of extracellular matrix, and contributes to esophageal epithelial-to-mesenchymal transitions (EMTs) in vitro ${ }^{10,14-18}$ and in vivo. ${ }^{8,19,20}$ In vitro models have shown that TGF- $\beta 1$ alters epithelial barrier function in other epithelial cell types, including columnar epithelium of the lung and pseudostratified epithelium of the epididymis and vas defrens; ${ }^{21-23}$ however, no study has evaluated the influence of TGF- $\beta 1$ on stratified squamous epithelial barriers including the esophageal epithelium. Therefore, we sought to determine the role of TGF- $\beta 1$ on epithelial barrier function in the pathogenesis of EoE. We hypothesized that TGF- $\beta 1$ regulates epithelial barrier dysfunction in EoE.

\section{RESULTS}

\section{TGF- $\beta 1$ alters the esophageal epithelial barrier}

To investigate the functional consequences of TGF- $\beta 1$ on esophageal epithelia, we measured the barrier by transepithelial electrical resistance (TEER) and paracellular permeability by $3 \mathrm{kDa}$ Fluorescein isothiocyanate dextran flux (FITC Flux) in immortalized human esophageal epithelial (EPC2-hTERT) cells grown in a physiologically relevant three-dimensional airliquid interface (3D-ALI) model in vitro where cells undergo stratification and squamation. We found that TGF- $\beta 1$ $\left(10 \mathrm{ng} \mathrm{ml}^{-1}\right)$ exposure resulted in a significant attenuation of barrier, as measured by TEER, compared with unstimulated control cells $\left(446.6 \pm 29.7\right.$ vs. $323.1 \pm 15.6 \mathrm{ohm} \cdot \mathrm{cm}^{2}$, Control vs. TGF- $\beta 110 \mathrm{ng} \mathrm{ml}^{-1}, N=8, P \leq 0.01$; Figure 1a). We evaluated the epithelial paracellular permeability using $3 \mathrm{kDa}$ FITC Flux and found a significant increase in paracellular flux in the epithelium exposed to TGF- $\beta 1\left(10 \mathrm{ng} \mathrm{ml}^{-1}\right)$ when compared with unstimulated cells ( $1.00 \pm 0$ vs. $1.47 \pm 0.15$-fold, Control vs. TGF- $\beta 110 \mathrm{ng} \mathrm{ml}^{-1}, N=4, P \leq 0.05$; Figure 1b). We performed a histological analysis of EPC2-hTERT cells grown in a physiologically relevant 3D-ALI model. H\&Estained sections of EPC2-hTERT cells grown in 3D-ALI had normal stratification and differentiation (Figure 1c, top panel). However, TGF- $\beta 1\left(10 \mathrm{ng} \mathrm{ml}^{-1}\right)$-treated cells grown in 3D-ALI had prominent cell separation, particularly in the basal and suprabasal layers (Figure 1c, bottom panel).

Because activation of the canonical TGF- $\beta 1$ pathway leads to phosphorylation of SMAD2/3, we performed western blot analysis of pSMAD2/3 to confirm the effect of TGF- $\beta 1$ at the signaling level in the 3 -D ALI model. We found that TGF- $\beta 1$ $\left(10 \mathrm{ng} \mathrm{ml}^{-1}\right)$ exposure resulted in an increase in pSMAD2/3 protein expression $(1.00 \pm 0.34$ vs. $2.16 \pm 0.46$, Control vs. TGF- $\left.\beta 110 \mathrm{ng} \mathrm{ml}^{-1}, N=4, P \leq 0.05\right)$ and a decrease in total
SMAD2/3 protein expression $(1.00 \pm 0.08$ vs. $0.55 \pm 0.03$, Control vs. TGF- $\left.\beta 110 \mathrm{ng} \mathrm{ml}^{-1}, \quad N=4, P \leq 0.01\right)$ when compared with unstimulated control cells, as measured by densitometry, indicating that TGF- $\beta 1$ activates SMAD2/3 via phosphorylation in the in vitro 3-D ALI model (Figure 1d-f).

\section{TGF- $\beta 1$ attenuates expression of tight junction claudin-7 in vitro}

In light of the functional barrier changes observed after exposure to TGF- $\beta 1$, we sought to understand the expression patterns of various epithelial cell-cell junction barrier molecules in 3D-ALI cells following TGF- $\beta 1$ exposure. We analyzed transmembrane epithelial barrier molecule expression of the epithelial cell-cell junctions including tight junctions, adherens junctions, and desmosomes using real-time reverse transcription polymerase chain reaction (RT-PCR). These molecules were targeted because they are the transmembrane proteins involved in cell-cell junctions important in epithelial barrier function. In particular, we performed an array analysis using real-time RT-PCR to determine which claudins were present in the esophageal epithelium using EPC2-hTERT cells. Consistent with previous literature in the field ${ }^{24-26}$ we found that claudin-1, -4 , and -7 were the predominantly expressed claudins in the esophageal epithelium differentiated at 3D-ALI (Figure 2a). We subsequently found the specific and significantly attenuated expression of claudin-7 (CLDN7) mRNA in 3D-ALI cells exposed to TGF- $\beta 1\left(10 \mathrm{ng} \mathrm{ml}^{-1}\right)$ when compared with unstimulated cells $(0.93 \pm 0.10$ vs. $0.42 \pm 0.02$, Control vs. TGF- $\beta 110 \mathrm{ng} \mathrm{ml}^{-1}, N=3, P \leq 0.01$; Figure $2 \mathbf{b}$ ). However, no significant differences were observed in other epithelial barrier molecules, including adherens junction components (E-Cadherin), desmosomes (desmoglein-1, desmoglein-2, and desmoglein-3), or tight junction components (claudin-1, claudin-4, occludin, and zonula occluden-1; Table 1). In addition, there were no significant differences in mesenchymal genes including connective tissue growth factor or alpha smooth muscle actin. There was, however, a significant increase in $\mathrm{N}$-Cadherin. With no concomitant decrease in E-Cadherin in our cells following 5 days of culture at 3D-ALI in the presence of TGF- $\beta 1$, this does not meet the definition of $\mathrm{EMT}^{27}$ (Table 1). Western blot analysis of cell lysates showed consistent findings, with a significant decrease in protein expression of CLDN7 relative to unstimulated cells as measured by densitometry $\left(1.00 \pm 0.17\right.$ vs. $0.28 \pm 0.12$, Control vs. TGF- $\beta 110 \mathrm{ng} \mathrm{ml}^{-1}$, $N=3, P \leq 0.05$; Figure $2 \mathbf{c}, \mathbf{d})$. To determine whether inhibition of the TGF- $\beta 1$-SMAD pathway would protect against the TGF$\beta 1$-mediated attenuation in CLDN7, we exposed esophageal epithelial cells to SB431542, a selective inhibitor of TGF- $\beta$ type 1 receptor (TGFBR1), before TGF- $\beta 1$. We found that, when cells were exposed to TGF- $\beta 1$, there was an expected attenuation in CLDN7; however, when cells were exposed to TGF- $\beta$ type 1 receptor inhibitor before TGF- $\beta 1$, they were protected from the TGF- $\beta 1$-mediated CLDN7 attenuation, indicating that the TGF- $\beta 1$ pathway directly influences the attenuation of CLDN7 ( $1.00 \pm 0$ vs. $0.08 \pm 0.02$ vs. $1.38 \pm 0.17$, Control vs. TGF- $\beta 1$ $10 \mathrm{ng} \mathrm{ml}^{-1}$ vs. TGF- $\beta$ RI $5 \mu \mathrm{m}, N=4, P \leq 0.01$; Figure 2e). 
a

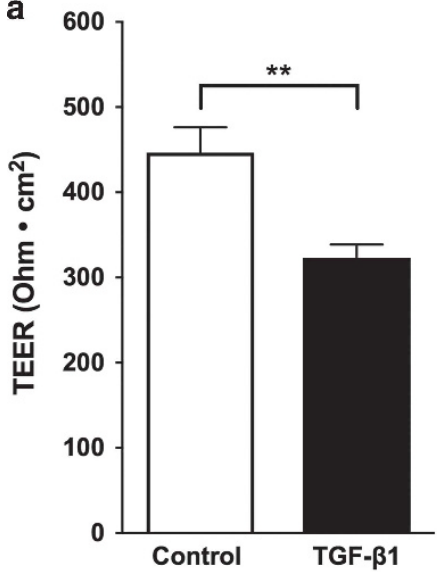

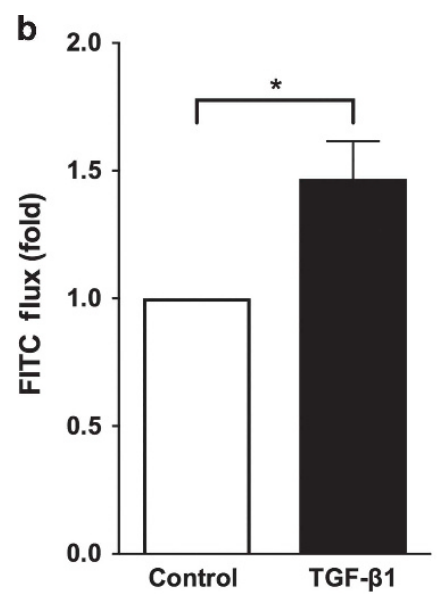

C

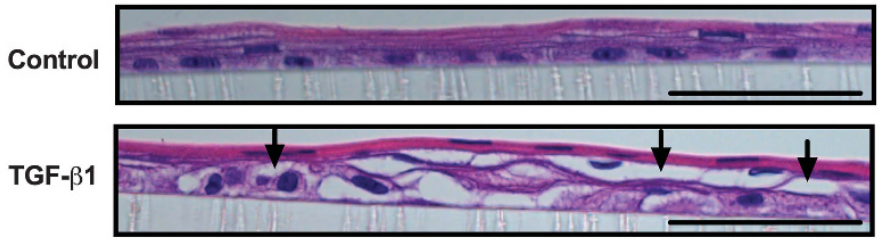

d

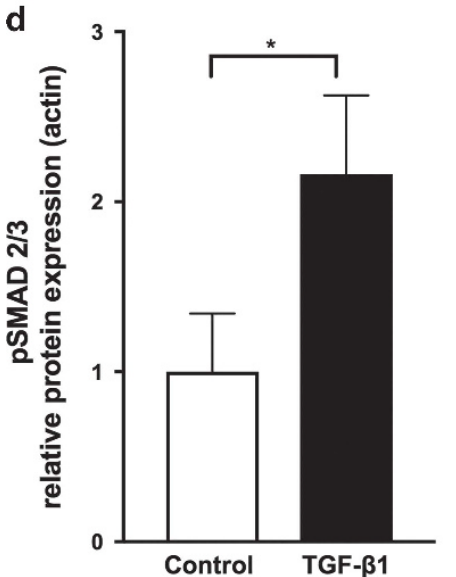

e

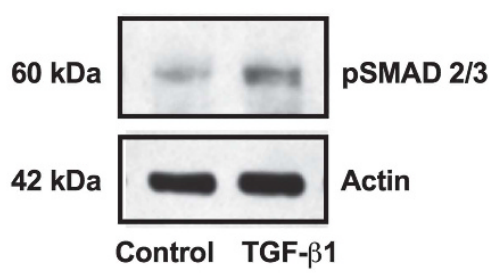

\begin{tabular}{|l|l|l|l|}
\hline $\begin{array}{l}\text { Relative protein } \\
\text { expression (actin) }\end{array}$ & Control & $\begin{array}{c}\text { TGF- } \beta 1 \\
\left(10 \text { ng ml }^{-1}\right)\end{array}$ & Significance \\
\hline pSMAD2/3 & $1.00 \pm 0.34$ & $2.16 \pm 0.46$ & $P \leq 0.05$ \\
\hline Total SMAD2/3 & $1.00 \pm 0.08$ & $0.55 \pm 0.03$ & $P \leq 0.01$ \\
\hline
\end{tabular}

Figure 1 Transforming growth factor- $\beta 1$ (TGF- $\beta 1$ ) diminishes esophageal epithelial barrier. Using immortalized human esophageal epithelial (EPC2-TERT) cells in a stratified squamous three-dimensional air-liquid interface (3D-ALI) culture, transforming growth factor- $\beta 1$ (TGF- $\beta 1 ; 10 \mathrm{ng} \mathrm{ml}{ }^{-1}$ ) diminished barrier as measured by (a) transepithelial electrical resistance (TEER) and increased permeability as measured by (b) $3 \mathrm{kDa}$ Fluorescein isothiocyanate dextran paracellular flux (FITC Flux; $N=4-8,{ }^{*} P \leq 0.05,{ }^{* *} P \leq 0.01$ ). (c) Hematoxylin and eosin (H\&E)-stained sections from EPC2-TERT cells grown in 3D-ALI culture and treated with TGF- $\beta 1\left(10 \mathrm{ng} \mathrm{ml}^{-1}\right)$. Arrows indicate prominent cellular separation. Black scale bar $=50 \mu \mathrm{m}$. $(\mathrm{d}) \mathrm{To}$ confirm that TGF- $\beta 1$ signaling is increased, we performed western blot densitometry that shows an increase in protein expression of phosphorylated SMAD2/3 (pSMAD2/3) when cells are exposed to TGF- $\beta 1\left(10 \mathrm{ng} \mathrm{m}^{-1}\right)$, indicating that TGF- $\beta 1$ activates SMAD2/3 via phosphorylation in the in vitro 3-D ALI model $\left(N=4,{ }^{\star} P \leq 0.05\right)$. (e) Representative western blot showing an increase in protein expression of pSMAD2/3 in vitro when exposed to TGF- $\beta 1\left(10 \mathrm{ng} \mathrm{ml}^{-1}\right)$. (f) Protein expression of pSMAD2/3 and total SMAD2/3 when EPC2-TERT cells exposed to TGF- $\beta 1$ (10 ng ml ${ }^{-1}$ ). Data are expressed as the mean fold change vs. unstimulated controls \pm s.e.m. Treatment with recombinant human TGF- $\beta 1$ (10 ng ml ${ }^{-1}$ ) occurred at the start of 3D-ALI exposure and during the process of differentiation and stratification on days 7 and 9.

\section{CLDN7 knockdown results in esophageal epithelial barrier dysfunction in vitro}

In order to assess whether the role of TGF- $\beta 1$ was mediated, at least in part, through the suppression of CLDN7 expression, we generated CLDN7 knockdown (KD) cells using an shRNAmediated approach and examined barrier function in these esophageal cells. To first validate the level of CLDN7 suppression in our cells, we examined CLDN7 mRNA and CLDN7 protein expression levels. We found our cells to have $97 \%$ reduction in CLDN7 mRNA expression (1.00 \pm 0 vs. $0.03 \pm 0.004$, shRNA control vs. shRNA CLDN7 KD, $N=3$, $P \leq 0.0001$ ) as compared with control cells (Figure 3d). This resulted in a $90 \%$ reduction in CLDN7 expression at the protein level $(1.00 \pm 0$ vs. $0.098 \pm 0.091$, shRNA control vs. shRNA CLDN7 KD, $N=3, P \leq 0.01$ ) as compared with control cells (Figure 3a-c). Specificity for CLDN7 was confirmed by 

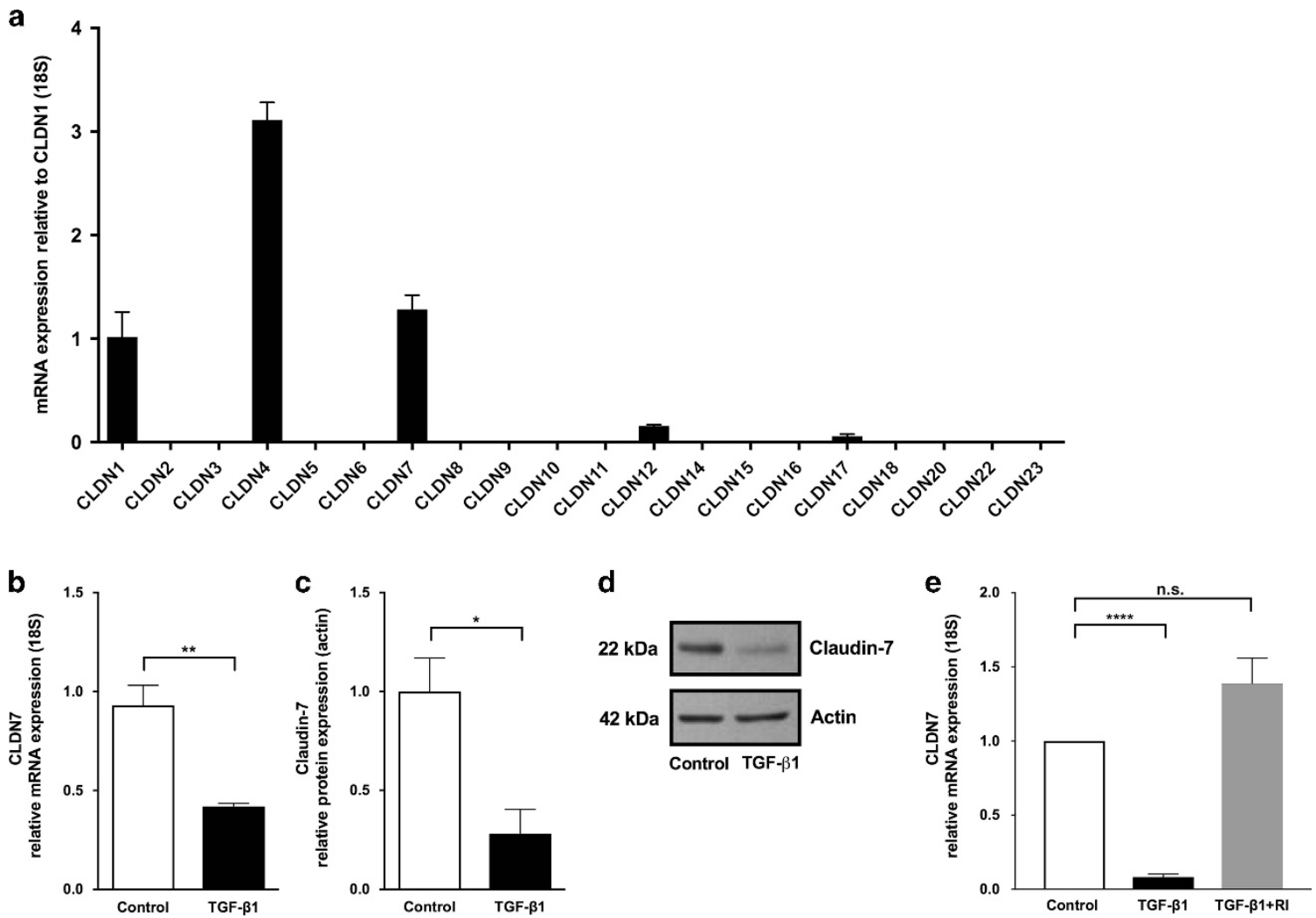

Figure 2 Transforming growth factor- $\beta 1$ (TGF- $\beta 1$ ) attenuates expression of Claudin-(CLDN) 7. (a) Claudin mRNA expression in immortalized human esophageal epithelial (EPC2-hTERT) cells as the mean fold change relative to CLDN1. CLDN1, 4, and 7 were the predominantly expressed claudin mRNAs in the esophageal epithelium differentiated and stratified in 3D-ALI culture. (b) TGF- $\beta 1$ exposure (10 ng ml $\left.{ }^{-1}\right)$ led to no significant effect on expression of selected epithelial barrier molecules, but decreased expression of CLDN7 mRNA and (c) CLDN7 protein in EPC2-hTERT cells at 3D-ALI $\left(N=3,{ }^{*} P \leq 0.05,{ }^{* *} P \leq 0.01\right)$. (d) Representative western blot demonstrates decreased CLDN7 protein in the presence of TGF- $\beta 1$ (10 ng ml $\left.{ }^{-1}\right)$. (e) EPC2-hTERT cells exposed to TGF- $\beta 1\left(10 \mathrm{ng} \mathrm{ml}^{-1}\right.$ ) lead to attenuation in CLDN7; however, when exposed to TGF- $\beta$ type 1 receptor inhibitor (TGF- $\beta$ RI; $5 \mu \mathrm{m}$ ) before TGF- $\beta 1$, cells were protected from the attenuation in CLDN7, indicating that the TGF- $\beta 1$ pathway directly influences the attenuation of CLDN7 $\left(N=4,{ }^{* \star \star \star} P \leq 0.0001\right)$.

assessing the expression of other related esophageal claudins at the protein level by western blot analysis, including claudin-1 ( $1.00 \pm 0$ vs. $1.16 \pm 0.28$, shRNA control vs. shRNA CLDN7 $\mathrm{KD}, N=2$, non-significant (n.s.)) and claudin- 4 (1.00 \pm 0 vs. $0.61 \pm 0.1$, shRNA control vs. shRNA CLDN7 KD, $N=2$, n.s.). No significant effects on these associated molecules were observed (Figure 3a,b).

Functional barrier assessments of CLDN7 knockdown cells in the 3D-ALI model were performed to evaluate the importance of this specific molecule on the esophageal epithelial barrier. We found a significant decrease in TEER ( $437.4 \pm 19.5$ vs. $336.0 \pm 23.5 \mathrm{ohm} \cdot \mathrm{cm}^{2}$, shRNA control vs. shRNA CLDN7 KD, $N=12, P \leq 0.01)$ and a parallel increase in the paracellular flux ( $1.00 \pm 0$ vs. $1.54 \pm 0.31$, shRNA control vs. shRNA CLDN7 $\mathrm{KD}, N=11, P \leq 0.05)$ when compared with control cells (Figure 4a,b). We performed a histological analysis of these cells in the 3D-ALI model. H\&E-stained sections of CLDN7 knockdown cells grown in 3D-ALI exhibit prominent cell separation, particularly in the basal and suprabasal layers (Figure $\mathbf{4 c}$, bottom panel) when compared with control cells, which displayed normal epithelial stratification (Figure 4c, top panel).
In addition, we generated CLDN7-overexpressing cells (pLKO.1-Puro claudin-7 ORF) and compared functional assessments in these esophageal cells in the presence and absence of TGF- $\beta 1$ in the 3-D ALI model. CLDN7-overexpressing cells, pLKO.1-Puro claudin-7 ORF, were validated and had a 4.9 -fold increase in mRNA expression and a 2.5 -fold increase in protein expression by western blot analysis when compared with control cells, pLKO.1-Puro EV. When pLKO.1Puro claudin-7 ORF cells were grown in the presence and absence of TGF- $\beta 1$, there was no significant decrease in TEER $\left(376.2 \pm 46.8\right.$ vs. $341.0 \pm 53.1 \mathrm{ohm} \cdot \mathrm{cm}^{2}$, pLKO.1-Puro claudin-7 ORF without TGF- $\beta 1$ vs. pLKO.1-Puro claudin-7 ORF with TGF- $\beta 110 \mathrm{ng} \mathrm{ml}^{-1}, N=5$, n.s.) or increase in the paracellular flux ( $1.00 \pm 0$ vs. $1.40 \pm 0.30$, pLKO.1-Puro claudin-7 ORF without TGF- $\beta 1$ vs. pLKO.1-Puro claudin-7 ORF with TGF- $\beta 110 \mathrm{ng} \mathrm{ml}^{-1}, N=4$, n.s.) (Figure 4d,e). We performed a histological analysis of CLDN7-overexpressing cells in the 3D-ALI model. H\&E-stained sections of these cells grown in 3D-ALI had normal stratification and differentiation (Figure 4f, top panel). CLDN7-overexpressing cells exposed to TGF- $\beta 1\left(10 \mathrm{ng} \mathrm{ml}^{-1}\right)$ in the $3 \mathrm{D}$-ALI model did not exhibit the same degree of cell separation as either EPC-hTERT cells 
Table 1 Expression of tight junction, adherens junction, desmosome, and mesenchymal genes in TGF- $\beta 1$-exposed EPC2-hTERT cells

\begin{tabular}{|c|c|c|}
\hline Name & $\begin{array}{l}\text { Fold change } \pm \text { s.e.m. } \\
\text { TGF- } \beta 1\left(10 \mathrm{ng} \mathrm{ml}^{-1}\right)\end{array}$ & Significance \\
\hline \multicolumn{3}{|l|}{ Tight junction } \\
\hline Claudin-1 & $1.27 \pm 0.13$ & n.s. \\
\hline Claudin-4 & $0.63 \pm 0.12$ & n.s. \\
\hline Claudin-7 & $0.45 \pm 0.02$ & $P \leq 0.01$ \\
\hline Occludin & $0.91 \pm 0.14$ & n.s. \\
\hline Zonula occluden-1 & $0.79 \pm 0.16$ & n.s. \\
\hline \multicolumn{3}{|l|}{ Adherens junction } \\
\hline E-Cadherin & $1.04 \pm 0.01$ & n.s. \\
\hline \multicolumn{3}{|l|}{ Desmosome } \\
\hline Desmoglein-1 & $1.09 \pm 0.30$ & n.s. \\
\hline Desmoglein-2 & $1.42 \pm 0.17$ & n.s. \\
\hline Desmoglein-3 & $1.14 \pm 0.33$ & n.s. \\
\hline \multicolumn{3}{|l|}{ Mesenchymal } \\
\hline Connective tissue growth factor & $0.88 \pm 0.33$ & n.s. \\
\hline Smooth muscle $\alpha$ actin & $1.16 \pm 0.23$ & n.s. \\
\hline N-Cadherin & $49.69 \pm 11.12$ & $P \leq 0.05$ \\
\hline
\end{tabular}

Abbreviations: EPC2-hTERT, immortalized human esophageal epithelial cell; n.s., non-significant; TGF- $\beta 1$, transforming growth factor- $\beta 1$.

Data are expressed as the mean fold change vs. unstimulated controls \pm s.e.m. exposed to TGF- $\beta 1$ or CLDN7 KD cells (Figure $4 \mathbf{f}$, bottom panel). These results show that overexpression of CLDN7 in the presence of TGF- $\beta 1$ will partially but not completely protect the epithelial barrier and indicate that TGF- $\beta 1$ impairs the barrier in part through a CLDN7-dependent manner. Our findings suggest that in the setting of attenuated CLDN7, even in the absence of other potential effects of TGF- $\beta 1$, epithelial barrier defects exist. This finding suggests that suppression of CLDN7 in response to TGF- $\beta 1$ exposure has an important role in esophageal epithelial barrier integrity in vitro.

\section{CLDN7 expression is attenuated in pediatric subjects with active EoE}

We next sought to evaluate the clinical relevance of these in vitro findings. Pediatric subjects were characterized by disease activity based on clinical symptoms and histopathology. We evaluated esophageal biopsies from active EoE subjects $(N=7)$, inactive EoE subjects $(N=6)$, and healthy controls $(N=10)$.

Consistent with our in vitro findings, we found that CLDN7 mRNA expression was significantly decreased in subjects with active EoE compared with that in control subjects. In addition, following successful treatment of EoE, in inactive EoE subjects, CLDN7 mRNA expression was restored to similar levels as in our control subjects $(1.00 \pm 0.10$ vs. $0.30 \pm 0.10$ vs. $0.97 \pm 0.13$, control subjects vs. active EoE subjects vs. inactive EoE, $N=6-10$ per group, $P \leq 0.001$; Figure 5). We next performed immunofluorescent staining for CLDN7 protein in esophageal biopsies in order to characterize its expression pattern and localization. Control and inactive EoE subjects showed a crisp

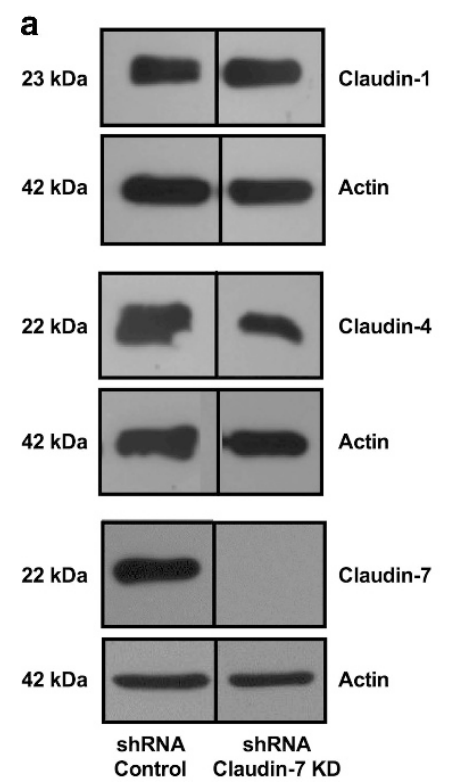

b

\begin{tabular}{|l|l|l|}
\hline $\begin{array}{l}\text { Relative protein } \\
\text { expression (actin) }\end{array}$ & $\begin{array}{l}\text { shRNA Claudin-7 KD } \\
\text { fold change } \pm \text { s.e.m. }\end{array}$ & Significance \\
\hline Claudin-1 & $1.16 \pm 0.28$ & n.s. \\
\hline Claudin-4 & $0.61 \pm 0.1$ & n.s. \\
\hline Claudin-7 & $0.098 \pm 0.091$ & $P \leq 0.01$ \\
\hline
\end{tabular}
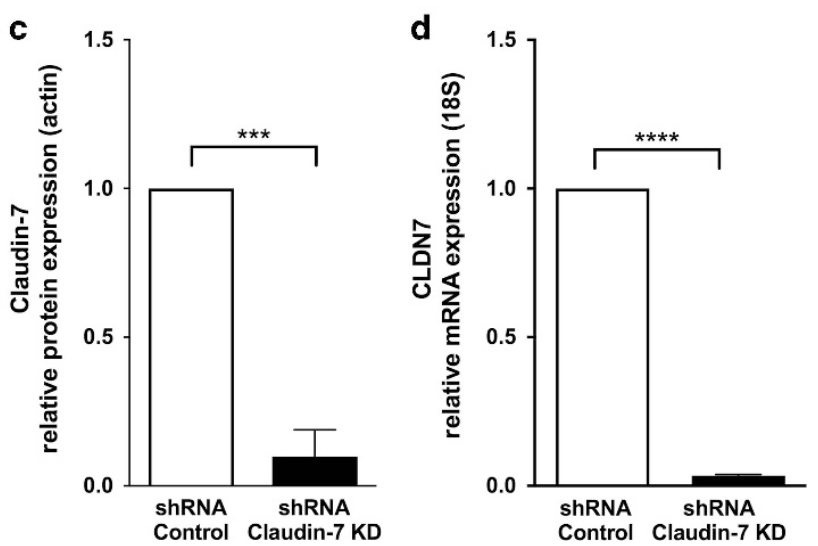

Figure 3 Claudin-7 (CLDN7) knockdown validation. CLDN7 knockdown cells were generated with short hairpin ribonucleic acid (shRNA) constructs targeted against CLDN7 mRNA to determine the role of CLDN7 in epithelial barrier dysfunction independent of transforming growth factor- $\beta 1$ (TGF- $\beta 1$ ). (a) Western blot to assess specificity for CLDN7 was confirmed by assessing the expression esophageal claudins (claudin-1, -4 , and -7 ) at the protein level by western blot analysis on scrambled shRNA control and CLDN7 knockdown cells. (b) No significant effects on claudin-1 and -4 were observed. CLDN7 knockdown cells resulted in (c) $90 \%$ reduction in CLDN7 protein expression and (d) a 97\% reduction in CLDN7 mRNA expression. 


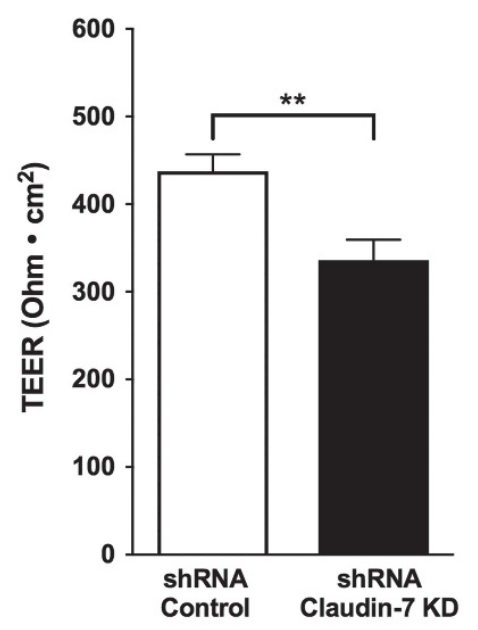

b

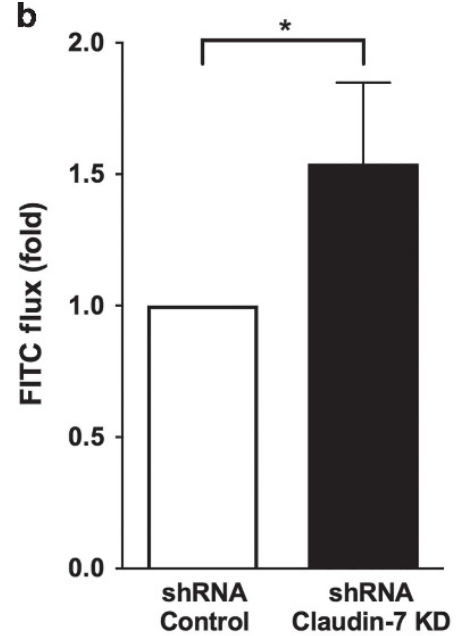

C

shRNA Control

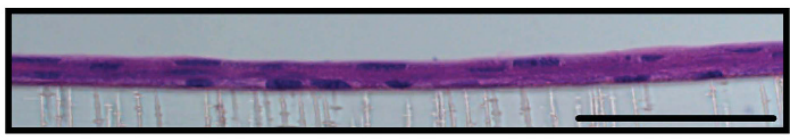

shRNA Claudin-7 KD

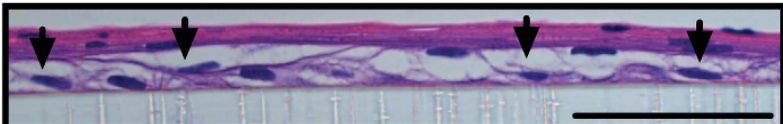

d

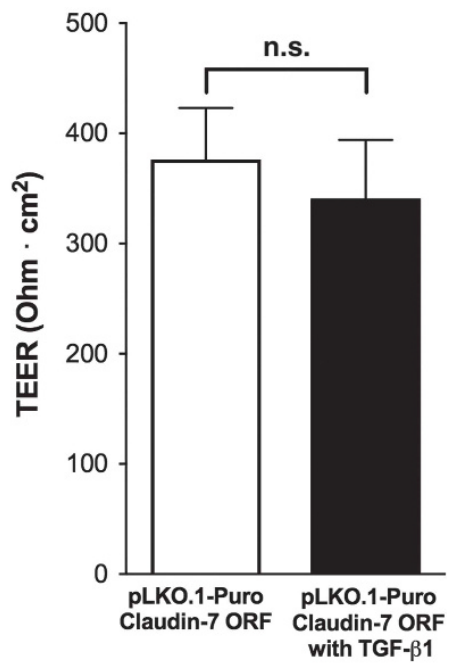

e

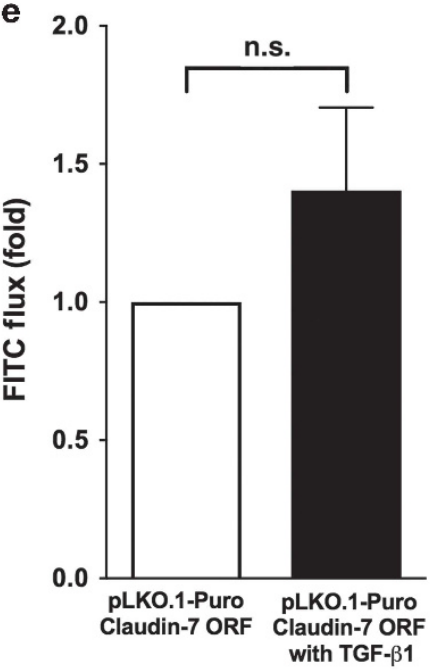

$\mathbf{f}$

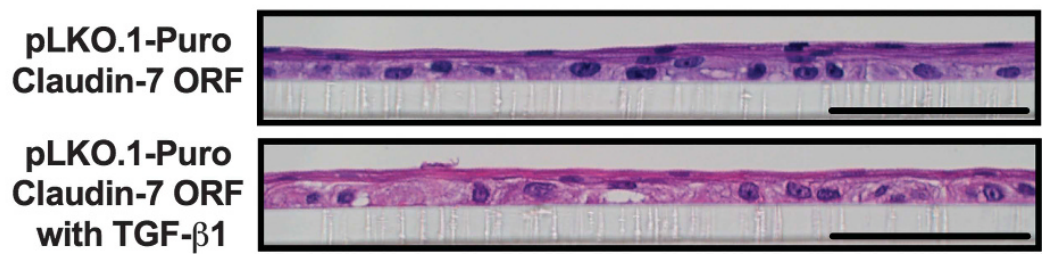

Figure 4 Claudin-7 (CLDN7) knockdown (KD) results in diminished esophageal epithelial barrier function. Knockdown of CLDN7 diminished barrier function as measured by (a) transepithelial electrical resistance (TEER) and increased permeability as measured by (b) $3 \mathrm{kDa}$ Fluorescein isothiocyanate dextran paracellular flux (FITC Flux; $N=11,{ }^{*} P \leq 0.05$, ${ }^{\star} P \leq 0.01$ ). (c) Hematoxylin and eosin (H\&E)-stained sections from CLDN7 KD cells grown in three-dimensional air-liquid interface (3D-ALI) culture. Arrows indicate prominent cellular separation. Black scale bar $=50 \mu \mathrm{m}$. These data suggest that in the setting of attenuated CLDN7, epithelial barrier defects exist. (d) CLDN7-overexpressing cells (pLKO.1-Puro claudin-7 ORF) were generated and functional assessments were done in the presence and absence of TGF- $\beta 1\left(10 \mathrm{ng} \mathrm{ml}^{-1}\right)$ in the 3D-ALI model. There was no significant decrease in TEER and (e) no significant increase in paracellular flux following TGF- $\beta 1$ exposure $(N=5$, n.s.). (f) H\&E-stained sections from CLDN7-overexpressing cells grown in 3D-ALI culture in the absence (top panel) and presence of TGF- $\beta 1$ (bottom panel). Black scale bar $=50 \mu \mathrm{m}$. 
continuous linear pattern outlining the cell membrane in the suprabasal layer of the epithelium with a honeycomb appearance. However, CLDN7 immunofluorescence in active EoE subjects showed a diffused granular perimembraneous pattern outlining the cell membrane in addition to increased staining present within the cytoplasm of the cells. This was particularly the case in cells of the suprabasal layers (Figure 6a-c).

\section{TGF- $\beta 1$ signaling increased in EoE}

Because activation of the canonical TGF- $\beta 1$ pathway leads to phosphorylation of SMAD2/3 and nuclear translocation of SMAD complexes that affect gene transcription, ${ }^{28}$ we evaluated pSMAD2/3 in active EoE subjects compared with that in controls and inactive EoE subjects. pSMAD2 staining was present in both the lamina propria and the epithelium of subjects with active EoE, similar to previously published findings. ${ }^{8}$ Future studies better powered to focus on the functional effects of lamina propria $\mathrm{pSMAD} 2 / 3$ should be pursued. However, for our focus on the effect of TGF- $\beta 1$ on the epithelium, we found increased nuclear pSMAD2 staining in esophageal epithelial cells in active EoE subjects compared with

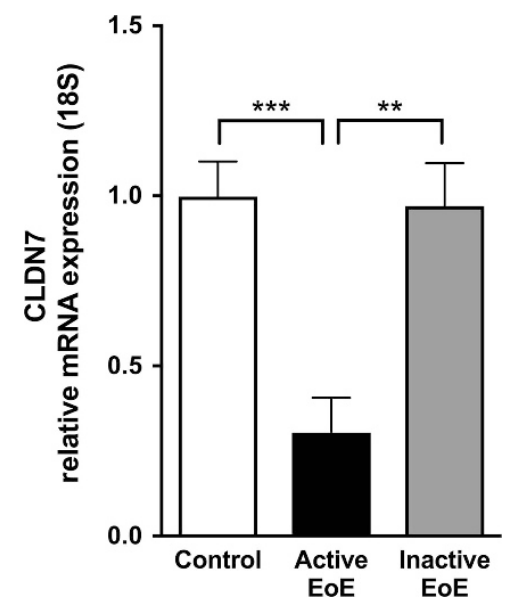

Figure 5 Claudin-7 (CLDN7) expression is decreased in pediatric subjects with eosinophilic esophagitis (EoE). CLDN7 mRNA is decreased in active $\operatorname{EoE}(N=7)$ compared with control subjects $(N=10)$. Levels returned to near normal following successful clinical treatment (inactive EoE, $\left.N=6 ;{ }^{* *} P \leq 0.01,{ }^{* \star *} P \leq 0.001\right)$. that in control and inactive $\operatorname{EoE}(500 \pm 54$ vs. $695 \pm 61$ vs. $504 \pm 35$ positively stained epithelial cells per high-power field, $N=3 \times 3$ fields of $\times 40$ view, $P \leq 0.05$; Figure $7 \mathbf{a}-\mathbf{d}$ ), indicating an increased TGF- $\beta 1$ signaling in the epithelium of subjects with active EoE. In addition, semiquantitative analysis of pSMAD2/3 protein expression by western blot analysis was consistent with these findings, with increased expression in active EoE when compared with control and inactive EoE subjects as measured with densitometry $(1.17 \pm 0.20$ vs. $3.17 \pm 0.64$ vs. $1.88 \pm 0.47$, control subjects vs. active EoE subjects vs. inactive EoE subjects, $N=6$ per group, $P \leq 0.05$; Figure 7e,f). To determine whether the regulation of SMAD2/3 is at the activation or the expression level, total SMAD2/3 was also assessed by western blot analysis in a cohort of these samples. There was no significant difference in total SMAD2/3 protein expression observed between control, active, and inactive EoE subjects $(1.00 \pm 0.41$ vs. $2.06 \pm 0.70$ vs. $2.92 \pm$ 1.21, normal subjects vs. active EoE subjects vs. inactive EoE subjects, $N=3-4$ per group, n.s.), indicating that there is an increase in the activation of SMAD2/3 by phosphorylation in the active EoE subjects (Figure 7g).

\section{DISCUSSION}

In this study, we demonstrate that TGF- $\beta 1$ leads to functional esophageal epithelial barrier defects in vitro. We show that esophageal epithelial cells cultured in 3D-ALI-stratified squamous cultures exposed to TGF- $\beta 1$ led to a specific attenuation of CLDN7 expression and that shRNA-mediated knockdown results in barrier defects, indicating a role for CLDN7 in maintaining epithelial barrier integrity. Notably, we demonstrate that CLDN7 expression is decreased and pSMAD2/3 is increased in pediatric subjects with active EoE when compared with control and inactive EoE subjects. The results herein suggest that the downregulation of CLDN7 by TGF- $\beta 1$ has a role in epithelial barrier dysfunction in EoE.

Our data show that, in the presence of TGF- $\beta 1$, TEER decreases and $3 \mathrm{kDa}$ FITC Flux increases, suggesting that TGF$\beta 1$ leads to an impaired epithelial barrier. Recent clinical studies implicate epithelial barrier dysfunction in the pathogenesis of EoE, including dilated intercellular spaces and decreased electrical impedance in subjects with active EoE. ${ }^{5,29,30}$ In addition, in translational studies, decreased expression of
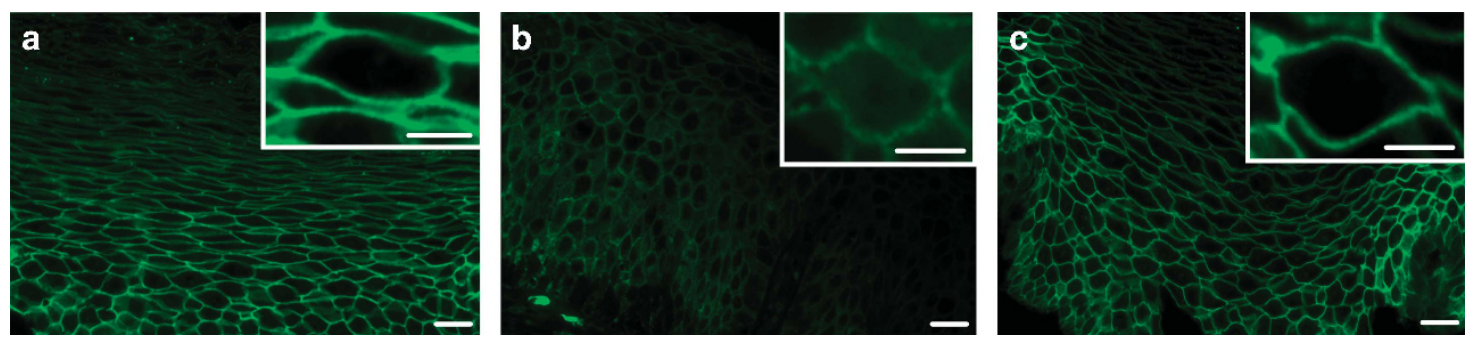

Figure 6 Claudin-7 (CLDN7) immunofluorescence in pediatric subjects. Immunofluorescent staining of CLDN7 protein in human esophageal biopsies from pediatric (a) control (b) active eosinophilic esophagitis (EoE) and (c) inactive EoE subjects. Immunofluorescence of (b) active EoE shows a diffused granular perimembraneous pattern outlining the cell membrane with staining present within the cytoplasm of the cells in the suprabasal layer when compared with (a) control and (c) inactive EoE subjects, which show a continuous linear pattern outlining the cell membrane in the suprabasal layer of the epithelium with a honeycomb appearance. Images at $\times 400$ magnification. White scale bar $=20 \mu \mathrm{m}$. White scale bar in inset image $=\mu \mathrm{m}$. 

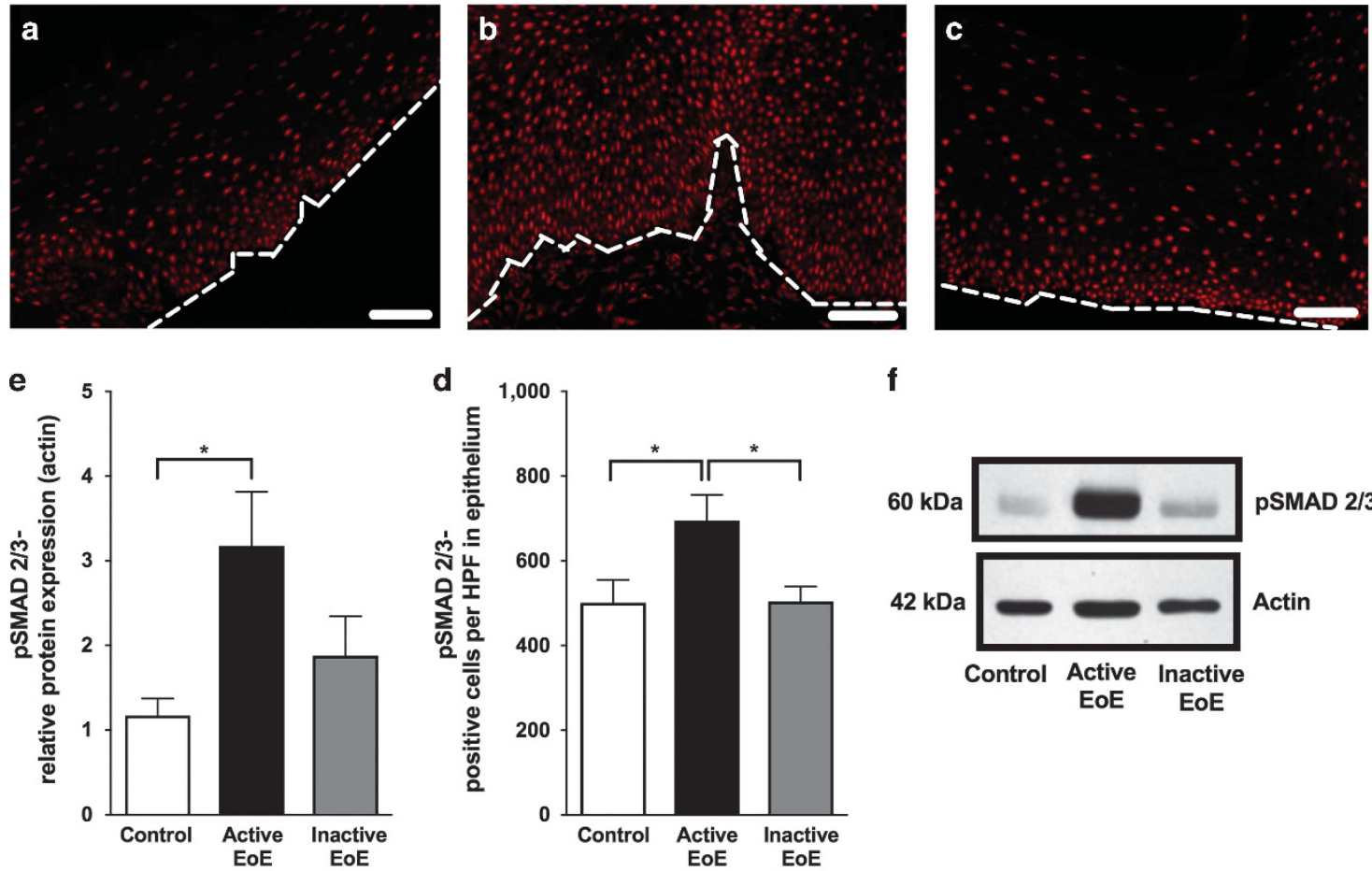

f

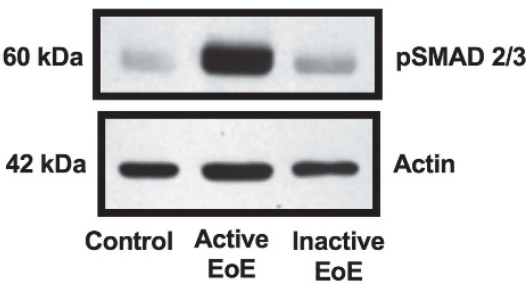

\begin{tabular}{|c|c|c|c|c|}
\hline $\begin{array}{l}\text { Relative protein } \\
\text { expression (actin) }\end{array}$ & Control & Active EoE & Inactive EoE & Significance \\
\hline pSMAD2/3 & $1.17 \pm 0.20$ & $3.17 \pm 0.64$ & $1.88 \pm 0.47$ & $P \leq 0.05$ \\
\hline Total SMAD2/3 & $1.00 \pm 0.41$ & $2.06 \pm 0.70$ & $2.92 \pm 1.21$ & n.s. \\
\hline
\end{tabular}

Figure 7 Phosphorylated SMAD2/3 (pSMAD2/3) in pediatric subjects. Immunofluorescent staining of pSMAD2/3 in human esophageal biopsies from (a) control, (b) active eosinophilic esophagitis (EoE), and (c) inactive EoE subjects. (a-c) At $\times 200$ magnification, white scale bar $=50 \mu \mathrm{m}$. White dotted line represents basal lamina. (d) Quantification shows increased positive cells per high-power field of pSMAD2/3 staining in active EoE compared with control and inactive EoE. (e) Western blot densitometry shows an increase in protein expression of pSMAD2/3 in active EoE vs. control and inactive EoE. (f) Western blot showing an increase in protein expression of pSMAD2/3 in active EoE vs. control and inactive EoE. (g) Relative protein expression of pSMAD2/3 and total SMAD2/3 in active EoE vs. control and inactive EoE.

junctional cell-cell adhesion complex molecules, such as desmoglein and barrier-forming filaggrin, further suggests an impaired epithelial barrier in EoE., ${ }^{3,4,7,31}$ Some of these studies have focused on the impact of the type- 2 cytokine interleukin-13 as a mediator of the negative regulation of epithelial barrier molecules associated with esophageal epithelium. ${ }^{3,4}$ Our study adds to the growing body of evidence that altered epithelial barrier has a role in the pathogenesis of EoE and indeed is the first study to examine the importance of CLDN7 in esophageal epithelial barrier function. Other studies have shown important roles for this molecule in the simple columnar epithelium of the colon and the cuboidal epithelium of the salivary glands. ${ }^{32,33}$ In vitro models examining the role of TGF- $\beta 1$ and impaired epithelial barrier function have been evaluated in other epithelia types, including the columnar epithelia of the lung, pseudostratified epithelium of the epididymis and vas defrens; however, this has not been previously examined in the stratified epithelium or indeed in the esophagus. ${ }^{21-23}$ Our study is the first to show the effect of TGF- $\beta 1$ on altered epithelial barrier function and specifically the key role of CLDN7 in the esophagus. Previous EoE studies have shown that TGF- $\beta 1$ has a role in esophageal remodeling, participates in esophageal smooth muscle contraction, stimulates fibroblast secretion of the extracellular matrix, and contributes to esophageal EMT. ${ }^{8,10,14-20}$ Our findings suggest that it is possible that chronic TGF- $\beta 1$-mediated altered esophageal epithelial barrier or increased esophageal epithelial permeability may allow the passage of allergens that enhances antigen presentation and immune activation and contributes in a previously unconsidered way to the chronicity of disease in EoE patients, although this would require further examination outside the remit of the current studies.

The findings in our study demonstrate that CLDN7 is downregulated both at the transcriptional and translational/ post-translational level in the presence of TGF- $\beta 1$. The claudin family of proteins is a transmembrane protein found in tight junctions that fall into two functional categories: barrierforming claudins that serve to tighten the barrier or poreforming claudins that increase permeability. ${ }^{34}$ Tight junctions serve as a barrier to paracellular permeability by forming a seal between epithelial cells and are important for the integrity of the epithelial barrier. ${ }^{34}$ CLDN7 is a barrier-forming claudin found 
in the epithelium of a variety of tissues. ${ }^{34}$ Several previous studies have shown that claudin- 1 and claudin- 4 , which are both barrier-forming claudins, are affected in in vitro models of gastroesophageal reflux disease in conjunction with increased permeability and decreased TEER, indicating a disrupted epithelial barrier. ${ }^{24,25}$ In addition, the esophageal epithelium in subjects with gastroesophageal reflux disease has significantly decreased claudin- 1 and claudin- 4 expression. ${ }^{26}$ After exposure to TGF- $\beta 1$ in vitro, we did not see a significant decrease in claudin-1 or claudin-4, which was previously shown in subjects with gastroesophageal reflux disease. Instead, we observed a significant and specific decrease in CLDN7, indicating that this is specific for TGF- $\beta 1$ signaling. In addition, in pediatric subjects with active EoE, we found that CLDN7 expression was significantly decreased as compared with control subjects, suggesting that the attenuation in CLDN7 may be specific to TGF- $\beta 1$ signaling in EoE and is important for esophageal barrier function.

In pediatric subjects with active EoE, we show that pSMAD2/ 3 is increased when compared with normal subjects and inactive EoE subjects, suggesting an increased TGF- $\beta 1$ signaling activity in the esophageal epithelium in active EoE. This is consistent with previous studies that have shown increased TGF- $\beta 1$ and pSMAD2/3 in active EoE, with the cellular source of TGF- $\beta 1$ being eosinophils, mast cells, and epithelial cells. ${ }^{8-11}$ In the canonical SMAD-dependent TGF- $\beta 1$ signaling pathway, binding of TGF- $\beta 1$ to TGF- $\beta$ receptors I and II allows TGF- $\beta$ receptor II to trans-phosphorylate TGF- $\beta$ receptor I leading to the phosphorylation of SMAD 2 and $3 .^{28}$ pSMAD2/3 complexes with the common SMAD4 and translocate into the nucleus. ${ }^{28}$ SNAI1, a transcription repressor, in complex with SMAD in the canonical TGF- $\beta 1$ signaling pathway, has been shown to target the gene promoter of several tight junction molecules, specifically claudin- 3 and E-cadherin in breast epithelial cells. ${ }^{35}$ In other systems, SNAI1 has a role in transcriptional repression of CLDN7. ${ }^{36-38}$ Other regulators of CLDN7 include hepatocyte nuclear factor 4 alpha. ${ }^{33}$ Therefore, a potential mechanism for the attenuation of CLDN7 is through the TGF- $\beta 1$ signaling pathway, with induction of the SMAD/ SNAI1 transcriptional repressor complex leading to the transcriptional repression of CLDN7 with resulting epithelial barrier dysfunction. Specifically, in vitro lung injury models revealed that TGF- $\beta 1$ reduced levels of claudin $-5{ }^{21}$ In vitro models of the vas deferens, which is a columnar epithelium, have shown that TGF- $\beta 1$ disrupts epithelial barrier with attenuation in CLDN7. ${ }^{23}$ Our study shows a specific attenuation of CLDN7 and decreased barrier function in esophageal epithelial cells after exposure to TGF- $\beta 1$. We show that in the esophagus, which is a stratified squamous epithelium, subjects with active EoE have a reduction in CLDN7 and alterations in the localization of CLDN7. We also demonstrate that knockdown of CLDN7 in esophageal epithelial cells resulted in a significant decrease in barrier function as measured by decreased TEER and increased paracellular permeability as measured by FITC Flux implicating the importance of this molecule in esophageal epithelial barrier function, and the lack of redundancy with other claudin molecules expressed in the esophagus. Overall, our data suggest that CLDN7 has a key role in maintaining the esophageal epithelial barrier function.

There are limitations to our study. First, our findings of esophageal epithelial barrier dysfunction are from in vitro studies and those with EoE patient biopsies. Future functional studies evaluating mucosal integrity by intraluminal impedance in conjunction with evaluating cell adhesion molecules, such as CLDN7, and activation of the TGF- $\beta 1$ signaling pathway are further needed. Second, earlier studies illustrated a role for TGF- $\beta 1$ in EMT. ${ }^{20}$ Unique to original studies on submerged cells, the focus of this study was to determine the effects of TGF$\beta 1$ specifically on epithelial barrier in cells grown in an organotypic manner. Although cells exposed to TGF- $\beta 1$ in this 3D-ALI environment increased $\mathrm{N}$-cadherin expression, it did not decrease E-cadherin expression. Loss of E-cadherin is a key event in the EMT cascade. By definition, Kalluri and Weinberg ${ }^{39}$ classify EMT as a process in which an epithelial cell completely loses its polarized, barrier-forming identity in turn for a mesenchymal state that functionally includes enhanced migration and invasiveness, increased apoptotic resistance, and the greatly increased production of extracellular matrix components. Our studies found a specific and significant decrease in CLDN7, an increase in N-cadherin, and no change in E-cadherin immediately in response to TGF$\beta 1$ exposure. In future studies, longer-term exposure to TGF- $\beta 1$ at ALI culture may lead to a functional EMT-like process that will critically involve the loss of epithelial molecular and functional phenotypes. EMT has an important role in wound healing following inflammation and injury. Pathological fibrosis can arise from excessive wound healing, a process in which TGF- $\beta 1$ has been shown to have a key role. ${ }^{28}$ In EoE, studies have shown that TGF- $\beta 1$ has a role in esophageal remodeling, esophageal smooth muscle contraction, EMT, and fibroblast secretion of extracellular matrix in vitro ${ }^{10,14-18}$ and in vivo. ${ }^{8,19,20}$ Thus, TGF- $\beta 1$ may not only have a role in EoE as it relates to EMT and fibrosis, but also in epithelial barrier dysfunction.

In summary, our findings indicate a pathogenic role for TGF- $\beta 1$ in esophageal barrier dysfunction. TGF- $\beta 1$, which is elevated in EoE, leads to alterations in epithelial barrier function, specifically through diminishing CLDN7 expression. With the growing body of clinical evidence suggesting a role of altered barrier in EoE specifically, and in atopic diseases in general, our findings support a potential role for TGF- $\beta 1$ in this process. The advent of TGF- $\beta 1$ inhibiting therapeutics presents an opportunity to consider this novel therapeutic approach that could alter both fibrotic as well as barrier alterations in EoE.

\section{METHODS}

Human esophageal epithelial cell line in air-liquid interface culture system. EPC2-hTERT ${ }^{40}$ cells (kind gift from Drs Anil Rustgi and Hiro Nakagawa, University of Pennsylvania), CLDN7 knockdown (KD) cells, or CLDN7-overexpressing cells were used for cell culture studies. To generate a human CLDN7 expression construct, full-length CLDN7 open reading frame (ORF; NM_001307) was amplified from plasmid mEmerald-claudin7-C-12 (Plasmid 54041; Addgene, 
Cambridge, MA) by PCR using sense primer 5'-AAAGCTAGCAA TGGCCAATTCGGGCCTGCAGTT-3' (incorporating a Kozak translation initiation sequence and $5^{\prime} \mathrm{NheI}$ restriction site) and antisense primer 5'-TTTATGTTTCAGGTTCAGGGGGAGGTGTGGGAGG-3' CLDN7 ORF was digested to generate NheI-CLDN7-XbaI for subcloning into lentiviral $p L K O .1$-puro plasmid with CMV promoter (Addgene) linearized by $N h e \mathrm{I} / \mathrm{XbaI}$ restriction digest. Digested CLDN7 and linearized $p L K O .1$ vector were purified (WizardPrep Column, Promega, Madison, WI) for ligation using T4 DNA ligase (New England Biolabs, Ipswich, MA). Constructs were verified by sequencing (Molecular Biology Service Center, University Colorado) and packaged into lentiviral particles using 293TN cells (SBI, Palo Alto, CA) and MISSION Lentiviral Packaging mix as previously described (Sigma-Aldrich, St Louis, MO).

To develop CLDN7 knockdown cells, EPC2-hTERT cells were transduced with shRNA lentiviral constructs targeting CLDN7 and a scrambled shRNA as a control (MISSION TRC, Functional Genomics Core, University of Colorado, Boulder) as previously described. ${ }^{41}$ To develop CLDN7-overexpressing cells, EPC2-hTERT cells were transduced with the above-generated lentiviral construct containing pLKO-claudin-7-overexpressing constructs (pLKO.1-Puro claudin-7 ORF) as previously described. ${ }^{41}$ Forty-eight hours after transduction, cells were selected for stable integration using puromycin $\left(0.3 \mu \mathrm{g} \mathrm{ml}^{-1}\right.$, Sigma-Aldrich).

The 3D-ALI culture system was used, as previously described. ${ }^{4,42}$ In brief, EPC2-hTERT cells, CLDN7 knockdown cells, or CLDN7overexpressing cells were submerged in keratinocyte serum-free media (KSFM; Thermo Fisher, Waltham, MA) and grown to confluence on $0.4 \mu \mathrm{m}$ pore-size-permeable transwells (Corning, Corning, NY). Once the cells reached confluence, on day 2 , they were placed in highcalcium KSFM $\left(\left[\mathrm{Ca}^{2+}\right]=1.8 \mathrm{~mm}\right)$ for an additional 5 days to induce terminal differentiation. To induce stratification, media was removed from the upper chamber in order to expose the cells to air-liquid interface (ALI) for a 4-day period. Treatment with recombinant human TGF- $\beta 1$ (R\&D Systems, Minneapolis, MN, $10 \mathrm{ng} \mathrm{ml}^{-1}$ ) in the basal chamber occurred at the start of 3D-ALI exposure and during the process of differentiation and stratification on days 7 and 9. Cells were collected for analysis of RNA or protein expression and for histologic analysis as previously described. ${ }^{4}$

Esophageal epithelial barrier measurements. Functional assays of barrier were performed on the 3D-ALI culture system assessing TEER with a commercial Ohmmeter (WPI, Sarasota, FL) as previously described. ${ }^{41}$ In vitro measurements for TEER were assessed on day 11 of cells grown at 3D-ALI in TGF- $\beta 1$-treated cells, CLDN7 knockdown or CLDN7 overexpressing cells.

Paracellular $3 \mathrm{kDa}$ FITC Flux assays were also completed on TGF- $\beta 1$-treated EPC2-hTERT and CLDN7 knockdown or CLDN7 overexpressing cells that were grown at $3 \mathrm{D}$-ALI on $0.4 \mu \mathrm{m}$ permeable polyester membrane inserts on day 11 of culture. Following washing, Fluorescein isothiocyanate-Dextran $\left(62.5 \mu \mathrm{g} \mathrm{ml}^{-1}, 3 \mathrm{kDa}\right.$, Molecular Probes, Thermo Fisher, Waltham, MA) was placed into the apical chamber. Samples were harvested from the basal chamber every $30 \mathrm{~min}$ for $90 \mathrm{~min}$ after to determine the rate of flux. Fluorescent spectrophotometry was performed to analyze samples.

TGF- $\beta 1$ inhibition. EPC2-hTERT cells were cultured as previously described. ${ }^{40}$ EPC2-hTERT cells were seeded at 125,000 cells per well of a 24-well plate. Twenty-four hours after the cells were plated, they were washed and pre-treated with SB431542, a selective inhibitor of TGF- $\beta$ type 1 receptor (S4317, Sigma-Aldrich, $5 \mu \mathrm{m}$ ) for $4 \mathrm{~h}$. After $4 \mathrm{~h}$, the cells were treated with recombinant human TGF- $\beta 1$ (R\&D Systems, $10 \mathrm{ng} \mathrm{ml}^{-1}$ ) in combination with the selective TGF- $\beta$ RI inhibitor ( $\$ 4317$, Sigma-Aldrich, $5 \mu \mathrm{m}$ ) for $48 \mathrm{~h}$. Cells were harvested for mRNA analysis using RLT buffer from Qiagen RNeasy kits (Qiagen, Valencia, CA).

RNA isolation and quantitative RT-PCR. RNA from cells in 3D-ALI and human esophageal biopsies were isolated using RNeasy kit
(Qiagen) according to the manufacturer's instructions and cDNA made using a high-capacity cDNA Reverse Transcription Kit (Applied Biosystems, Foster City, CA). Junctional molecule expression was measured with real-time RT-PCR using TaqMan gene expression assays (Applied Biosystems) targeting E-Cadherin, desmoglein-1, desmoglein-2, desmoglein-3, claudin-1, claudin-4, CLDN7, occludin, zonula occluden-1, connective tissue growth factor, smooth muscle $\alpha$ actin, and N-Cadherin. Data were normalized to the house-keeping gene, $18 \mathrm{~S}$, and were calculated for each sample as relative quantity $\mathrm{RQ}=2^{-\Delta \Delta \mathrm{Ct}}$, where $\mathrm{Ct}$ is the cycle threshold.

Western blot analysis. Protein lysates were prepared using radioimmunoprecipitation assay buffer (Sigma-Aldrich) and protease inhibitor cocktail (Roche Diagnostics, Indianapolis, IN). Protein electrophoresis was performed using $12 \%$ polyacrylamide gels. Blots were probed with the primary antibody overnight and incubated with appropriate horseradish peroxidase-labeled secondary antibodies for $1 \mathrm{~h}$ at room temperature. Visualization was performed using a chemiluminescent detection system (SuperSignal West PICO, Thermo Fisher). Primary antibodies used include CLDN7 polyclonal rabbit antibody (\#34-9100, Invitrogen, Carlsbad, CA), pSMAD2/3 polyclonal rabbit antibody (\#8828, Cell Signaling Technology, Danvers, MA), SMAD2/3 monoclonal mouse antibody (\#610843, BD Biosciences, San Jose, CA), and $\beta$-Actin (\#8227, Abcam, Cambridge, MA). Quantification was assessed using comparative densitometry with $\beta$-actin as a loading control.

Immunohistochemical and immunofluorescent staining. Cells grown at 3D-ALI were fixed with $10 \%$ neutral-buffered formalin, processed, and paraffin-embedded. Sections were cut into $5 \mu \mathrm{M}$ sections and stained with H\&E (Sigma-Aldrich). Immunofluorescent staining was performed on formalin-fixed, paraffin-embedded esophageal biopsy samples that were cut into $5 \mu \mathrm{m}$ sections. Samples were de-paraffinized via sequential immersion with xylene followed by graded ethanol immersion and rehydration. Heat-induced antigen retrieval in sodium citrate buffer (Vector Laboratories, Burlingame, CA) was used. Sections were blocked in $5 \%$ bovine serum albumin in tris-buffered saline for $30 \mathrm{~min}$. Primary antibodies CLDN7 (1:100, \#51-900, Invitrogen) or pSMAD2 (1:2,000, \#3101, Cell Signaling Technology) were used and slides were incubated at $4{ }^{\circ} \mathrm{C}$ overnight. Slides were washed and incubated for $30 \mathrm{~min}$ at room temperature in secondary antibody of Alex Fluor 488 Goat anti-rabbit IgG or Alexa Fluor 555 Goat anti-rabbit IgG (Invitrogen). Slides were washed followed by counterstaining with 4',6-diamidino-2-phenylindole and mounted for visualization. Images were acquired using an Olympus IX83 microscope and cellSens v1.14 software (Center Valley, PA).

Characterization of human subject samples. Healthy control subjects underwent upper intestinal endoscopy for indications including abdominal pain, feeding difficulty, poor weight gain, and diarrhea, and had normal esophageal histology with a mean eosinophil count of 0 eosinophils per high-power field (eos/HPF). The mean age was $8.2 \pm 4.1$ years in these subjects. Active EoE subjects had symptoms of esophageal dysfunction and $\geq 15$ eos/HPF in whom other causes for eosinophilia had been ruled out according to consensus recommendations. ${ }^{1}$ Symptoms included abdominal pain, dysphagia, feeding difficulty, poor weight gain, and vomiting. Active EoE subjects had a mean eosinophil count of $46.5 \pm 34.9$ eos/HPF and the mean age was $8.7 \pm 5.1$ years. Inactive EoE subjects had an established diagnosis of EoE who underwent treatment with topical corticosteroids or dietary elimination with resolution of symptoms and $<15$ eos/HPF. These subjects had a mean eosinophil count of $1.8 \pm 2.9$ eos/HPF and the mean age was $7.2 \pm 4.0$ years. Written informed consent was obtained, and all human studies were approved by the Colorado Multi-Institutional Review Board.

Statistical analysis. Statistical analysis of data was performed by Students' $t$-test and one-way analysis of variance where appropriate. 
A $P$ value of $\leq 0.05$ was considered statistically significant, although in some cases higher levels of significance are noted when applicable $\left.{ }^{\star} P \leq 0.05,{ }^{* \star} P \leq 0.01,{ }^{* *} P \leq 0.001,{ }^{* * * *} P \leq 0.0001\right)$. GraphPad Prism 7 (GraphPad Software, LaJolla, CA) was used to perform statistical analysis and generate figures.

\section{ACKNOWLEDGMENTS}

We are grateful to our patients and families who consented to be in this study. We thank the physicians, nurses, and research assistants who contributed to this work by helping to recruit subjects and collect samples. We thank the members of all the participating laboratories for insightful discussions and critical comments. The EPC2-hTERT were a kind gift from Drs Anil Rustgi and Hiro Nakagawa, University of Pennsylvania. This study was supported by grants from the United States National Institutes of Health (NIH) 2T32DK067009-11 (N.N.), 1K24DK100303 (G.T.F.), K01DK106315 (J.C.M), and the American Partnership for Eosinophilic Disorders (J.C.M). This study is also funded by U54 Al117804, which is part of the Rare Disease Clinical Research Network (RDCRN), an initiative of the Office of Rare Disease Research (ORDR), NCATS, and is funded through collaboration between NCATS, NIAID, and NIDDK, as well as the patient advocacy groups American Partnership for Eosinophilic Disorders (APFED), CURED, and the Eosinophilic Family Coalition (EFC), which have collectively resulted in the Consortium of Eosinophilic Gastrointestinal Disease Researchers (CEGIR; G.T.F.). Manuscript contents are the authors' sole responsibility and do not necessarily represent official $\mathrm{NIH}$ views. The study sponsors had no role in the study design and in the collection, analysis, and interpretation of data.

\section{AUTHOR CONTRIBUTIONS}

Study concept and design N.N., S.D.F., S.P.C., G.T.F., and J.C.M.; acquisition of data N.N., S.D.F., K.A.B., J.A.H., K.E.C., and D.A.K.; analysis and interpretation of data N.N., S.D.F., L.E.G., S.P.C., G.T.F., and J.C.M.; drafting of the manuscript N.N., G.T.F., and J.C.M.; critical revision of the manuscript for important intellectual content N.N., S.D.F., S.P.C., G.T.F., and J.C.M.; statistical analysis N.N., S.D.F., and J.C.M.; obtained funding N.N., G.T.F., and J.C.M.; study supervision N.N., G.T.F., and J.C.M.

\section{DISCLOSURE}

The authors declared no conflict of interest.

(c) 2018 Society for Mucosal Immunology

\section{REFERENCES}

1. Liacouras, C.A. et al. Eosinophilic esophagitis: updated consensus recommendations for children and adults. J. Allergy Clin. Immunol. 128, 3-20 e6 (2011).

2. Collins, M.H. Histopathologic features of eosinophilic esophagitis and eosinophilic gastrointestinal diseases. Gastroenterol. Clin. North Am. 43, 257-268 (2014).

3. Blanchard, C. et al. Coordinate interaction between IL-13 and epithelial differentiation cluster genes in eosinophilic esophagitis. J. Immunol. 184, 4033-4041 (2010).

4. Sherrill, J.D. et al. Desmoglein-1 regulates esophageal epithelial barrier function and immune responses in eosinophilic esophagitis. Mucosal Immunol. 7, 718-729 (2014).

5. Katzka, D.A. et al. Effects of topical steroids on tight junction proteins and spongiosis in esophageal epithelia of patients with eosinophilic esophagitis. Clin. Gastroenterol. Hepatol. 12, 1824-9 e1 (2014).

6. van Rhijn, B.D., Kessing, B.F., Smout, A.J. \& Bredenoord, A.J. Oesophageal baseline impedance values are decreased in patients with eosinophilic oesophagitis. United European Gastroenterol. J. 1, 242-248 (2013).

7. Capocelli, K.E., Fernando, S.D., Menard-Katcher, C., Furuta, G.T., Masterson, J.C. \& Wartchow, E.P. Ultrastructural features of eosinophilic oesophagitis: impact of treatment on desmosomes. J. Clin. Pathol. 68, 51-56 (2015).
8. Aceves, S.S., Newbury, R.O., Dohil, R., Bastian, J.F. \& Broide, D.H. Esophageal remodeling in pediatric eosinophilic esophagitis. J. Allergy Clin. Immunol. 119, 206-212 (2007).

9. Straumann, A. et al. Anti-interleukin-5 antibody treatment (mepolizumab) in active eosinophilic oesophagitis: a randomised, placebo-controlled, double-blind trial. Gut 59, 21-30 (2010).

10. Aceves, S.S., Chen, D., Newbury, R.O., Dohil, R., Bastian, J.F. \& Broide, D.H. Mast cells infiltrate the esophageal smooth muscle in patients with eosinophilic esophagitis, express TGF-beta1, and increase esophageal smooth muscle contraction. J. Allergy Clin. Immunol. 126, 1198-204 e4 (2010).

11. Straumann, A. et al. Budesonide is effective in adolescent and adult patients with active eosinophilic esophagitis. Gastroenterology 139, 1526-1537. 37 e1 (2010).

12. Lucendo, A.J. et al. Subepithelial collagen deposition, profibrogenic cytokine gene expression, and changes after prolonged fluticasone propionate treatment in adult eosinophilic esophagitis: a prospective study. J. Allergy Clin. Immunol. 128, 1037-1046 (2011).

13. Mishra, A. et al. Esophageal remodeling develops as a consequence of tissue specific IL-5-induced eosinophilia. Gastroenterology 134, 204-214 (2008).

14. Beppu, L.Y., Anilkumar, A.A., Newbury, R.O., Dohil, R., Broide, D.H. \& Aceves, S.S. TGF-beta1-induced phospholamban expression alters esophageal smooth muscle cell contraction in patients with eosinophilic esophagitis. J. Allergy Clin. Immunol. 134, 1100-7 e4 (2014).

15. Muir, A.B. et al. Eosinophilic esophagitis-associated chemical and mechanical microenvironment shapes esophageal fibroblast behavior. J. Pediatr. Gastroenterol. Nutr. 63, 200-209 (2016).

16. Muir, A.B. et al. Esophageal epithelial cells acquire functional characteristics of activated myofibroblasts after undergoing an epithelial to mesenchymal transition. Exp. Cell Res. 330, 102-110 (2015).

17. Muir, A.B. et al. Esophageal epithelial and mesenchymal cross-talk leads to features of epithelial to mesenchymal transition in vitro. Exp. Cell Res. 319, 850-859 (2013).

18. Rieder, F. et al. T-helper 2 cytokines, transforming growth factor beta1, and eosinophil products induce fibrogenesis and alter muscle motility in patients with eosinophilic esophagitis. Gastroenterology 146, 1266-1277. e1-9 (2014).

19. Cho, J.Y. et al. Smad3-deficient mice have reduced esophageal fibrosis and angiogenesis in a model of egg-induced eosinophilic esophagitis. J. Pediatr. Gastroenterol. Nutr. 59, 10-16 (2014).

20. Kagalwalla, A.F. et al. Eosinophilic esophagitis: epithelial mesenchymal transition contributes to esophageal remodeling and reverses with treatment. J. Allergy Clin. Immunol. 129, 1387-96 e7 (2012).

21. Ohta, H., Chiba, S., Ebina, M., Furuse, M. \& Nukiwa, T. Altered expression of tight junction molecules in alveolar septa in lung injury and fibrosis. Am. J. Physiol. Lung Cell Mol. Physiol. 302, L193-L205 (2012).

22. Stammler, A., Muller, D., Tabuchi, Y., Konrad, L. \& Middendorff, R. TGFbetas modulate permeability of the blood-epididymis barrier in an in vitro model. PLOS ONE 8, e80611 (2013).

23. Pierucci-Alves, F., Yi, S. \& Schultz, B.D. Transforming growth factor beta 1 induces tight junction disruptions and loss of transepithelial resistance across porcine vas deferens epithelial cells. Biol. Reprod. 86, 36 (2012).

24. Chen, $X$. et al. Acidic bile salts modulate the squamous epithelial barrier function by modulating tight junction proteins. Am. J. Physiol. Gastrointest. Liver Physiol. 301, G203-G209 (2011).

25. Oshima, T., Koseki, J., Chen, X., Matsumoto, T. \& Miwa, H. Acid modulates the squamous epithelial barrier function by modulating the localization of claudins in the superficial layers. Lab. Invest. 92, 22-31 (2012).

26. Bjorkman, E.V., Edebo, A., Oltean, M. \& Casselbrant, A. Esophageal barrier function and tight junction expression in healthy subjects and patients with gastroesophageal reflux disease: functionality of esophageal mucosa exposed to bile salt and trypsin in vitro. Scand. J. Gastroenterol. 48, 1118-1126 (2013).

27. Kalluri, R. EMT: when epithelial cells decide to become mesenchymal-like cells. J. Clin. Invest. 119, 1417-1419 (2009).

28. Akhurst, R.J. \& Hata, A. Targeting the TGFbeta signalling pathway in disease. Nat. Rev. Drug Discov. 11, 790-811 (2012). 


\section{ARTICLES}

29. van Rhijn, B.D. et al. Proton pump inhibitors partially restore mucosal integrity in patients with proton pump inhibitor-responsive esophageal eosinophilia but not eosinophilic esophagitis. Clin. Gastroenterol. Hepatol. 12, 1815-23 e2 (2014).

30. Ravelli, A., Villanacci, V., Cadei, M., Fuoti, M., Gennati, G. \& Salemme, M. Dilated intercellular spaces in eosinophilic esophagitis. J. Pediatr. Gastroenterol. Nutr. 59, 589-593 (2014).

31. Simon, D., Radonjic-Hosli, S., Straumann, A., Yousefi, S. \& Simon, H.U. Active eosinophilic esophagitis is characterized by epithelial barrier defects and eosinophil extracellular trap formation. Allergy 70, 443-452 (2015).

32. Abe, A. et al. Interferon-gamma increased epithelial barrier function via upregulating claudin-7 expression in human submandibular gland duct epithelium. J. Mol. Histol. 47, 353-363 (2016).

33. Farkas, A.E. et al. HNF4alpha regulates claudin-7 protein expression during intestinal epithelial differentiation. Am. J. Pathol. 185, 2206-2218 (2015).

34. Gunzel, D. \& Yu, A.S. Claudins and the modulation of tight junction permeability. Physiol. Rev. 93, 525-569 (2013).

35. Vincent, T. et al. A SNAIL1-SMAD3/4 transcriptional repressor complex promotes TGF-beta mediated epithelial-mesenchymal transition. Nat. Cell Biol. 11, 943-950 (2009).
36. Lu, Y. et al. The effects of shRNA-mediated gene silencing of transcription factor SNAl1 on the biological phenotypes of breast cancer cell line MCF-7. Mol. Cell Biochem. 388, 113-121 (2014).

37. Mittal, M.K., Myers, J.N., Bailey, C.K., Misra, S. \& Chaudhuri, G. Mode of action of the retrogene product SNAI1P, a SNAIL homolog, in human breast cancer cells. Mol. Biol. Rep. 37, 1221-1227 (2010).

38. Pereira, F. et al. KDM6B/JMJJ3 histone demethylase is induced by vitamin $\mathrm{D}$ and modulates its effects in colon cancer cells. Hum. Mol. Genet. 20, 4655-4665 (2011).

39. Kalluri, R. \& Weinberg, R.A. The basics of epithelial-mesenchymal transition. J. Clin. Invest. 119, 1420-1428 (2009).

40. Harada, H. et al. Telomerase induces immortalization of human esophageal keratinocytes without p16INK4a inactivation. Mol. Cancer Res. 1, 729-738 (2003).

41. Saeedi, B.J. et al. HIF-dependent regulation of claudin-1 is central to intestinal epithelial tight junction integrity. Mol. Biol. Cell 26, 2252-2262 (2015).

42. Kc, K., Rothenberg, M.E. \& Sherrill, J.D. In vitro model for studying esophageal epithelial differentiation and allergic inflammatory responses identifies keratin involvement in eosinophilic esophagitis. PLOS ONE 10 e0127755 (2015). 